\title{
Synthesis 3,4-Dimethoxybenzyl-2,4-Dihydroxyphenyl Ketone from Eugenol
}

\author{
Matsjeh S., Anwar C., Sholikhah E. N., and Alimuddin A. A.
}

\begin{abstract}
The main content of clove oil is eugenol, amounting to $80-90 \%$. The aims this study to utilize eugenol from clove leave oil as raw material in the synthesis of 3,4-dimethoxybenzyl-2',4'-dihydroxyphenyl ketone with 3,4-dimethoxybenzylcyanide as intermediate compound. Converting eugenol into 3, 4-dimethoxybenzyl cyanide via several stages of reactions. Methylation of eugenol using dimethylsulphate and $\mathrm{NaOH}$ as catalyst was produced methyleugenol as much as $89.78 \%$ with a purity of $93.6 \%$. Isomerization of methyleugenol using alkaline potassium tertiary butoxide (t-BuOK) in the medium dimethyl sulfoxide (DMSO) was resulted in $87.24 \%$ yield methylisoeugenol with a purity of $88.89 \%$. Methylisoeugenol was oxydated using potassium dichromate $\left(\mathrm{K}_{2} \mathrm{Cr}_{2} \mathrm{O}_{7}\right)$ in a phase transfer catalyst system (PTC) by Polysorbate 80 into a 3,4dimethoxybenzaldehyde as much as $85.36 \%$ with a purity 83.46 \%. Reduction of 3.4-dimethoxybenzaldehyde using sodium borohidrat $\left(\mathrm{NaBH}_{4}\right)$ was producted 3.4dimethoxybenzylalcohol as much as $98 \%$ with a purity $100 \%$ level. The 3.4-dimethoxybenzylalcohol was halogenated using $\mathrm{SOCl}_{2}$ was producted 3.4-dimethoxybenzylchloride which reacted further with sodium cyanide to produce 3.4-dimethoxybenzylcyanide as much as $89.5 \%$ with a purity 99.24\%. The acylation reaction of acid 3,4-dimethoxyphenylacetic acid with resorcinol to 3,4-dimethoxybenzyl-2,4-dihydroxyphenyl ketone obtained is a white a solid product having a melting point of $171-172^{\circ} \mathrm{C}$. Rendamen generated from this experiment by $76 \%$.
\end{abstract}

Index Terms-Eugenol, 3.4-dimethoxybenzylcyanide, 3,4-dimethoxybenzyl-2', 4'dihydroxyphenylketone.

\section{INTRODUCTION}

Almost Indonesia's vast territory are very rich with aromatic essential oil plants.that essential oils which are the main content of aromatic compounds. One of them is the clove leaf oil. Clove leaf oil contains $80 \%$ eugenol. One of the very important chemical properties of eugenol is eugenolhave allyl group. The allyl group in eugenol, allowing eugenol can be converted into 3,4 - dimetoksibenzil carboxylic acid ( 3,4-dimethoxyphenyl acetic acid). The compound have the ability to act as a raw material to synthesis of isoflavones. Isoflavoneare subclass of flavonoids which are found in fruits, nuts, soybeans, and soybased products [1]. Isoflavones have demonstrated a variety of important biological activities, including

Manuscripit received April 14, 2014; revised June 30, 2014

Matsjeh S. and Anwar C. are with the Department of Chemistry, Faculty of Mathematics and Natural Sciences, Gadjah Mada University, Yogyakarta, Indonesia (e-mail : matsjeh@ugm.ac.id, irilwar@ugm.ac.id).

Sholikhah E. N. is with the Pharmacologi Department, Faculty of Medicine, Gadjah Mada University, Yogyakarta, Indonesia.

Alimuddin A. A. is with the Department of Chemistry, Faculty of Mathematics and Natural Sciences, Tanjungpura University, Tanjungpura, Indonesia. antioxidant [2], antibacterial [3], osteoporosis [4], anticancer effects [1]-[5]. The biological activity of these compounds is associated with beneficial effects on human health has become an interesting topic in the study of isoflavones including synthetic methods.

Many synthetic methods have been developed for the synthesis of isoflavones, among others are compounds chalcone [6], [7], chromon [8] and deoksibenzoin [9], [10]. The two most popular synthesis of isoflavon are thedeoxybenzoine. (2-hydroxyphenyl benzyl ketone) and the chalcon routes. The Starting material for synthesis isoflavoneviadeoxybenzoinroute usedbenzylcarboxylic acid (phenylacetic acid) and subtituted phenols. The formation of intermediates deoxybenzoine by Hoeben-Hoesch reaction between phenol and benzyl cyanide [11], [12].

This research relates to synthesis of 3, 4-dimethoxybenzyl -2, 4-dihydroxyphenyl ketone from eugenol through 3 , 4-dimethoxybenzylcyanide as an intermediate. Eugenol was choosen as a raw material, related to its structure which have allyl group attached in phenyl. The oxidation of allyl group will obtained substituted phenylacetic acid [12], [13].

\section{EXPERIMENTAL SECTION}

\section{A. Materials}

Clove leaf oil, eugenol, DMS, $\mathrm{NaOH}$, petroleum ether, dichloromethane, $\mathrm{K}_{2} \mathrm{Cr}_{2} \mathrm{O}_{7}, \mathrm{KMnO}_{4}, \mathrm{H}_{2} \mathrm{SO}_{4}, \mathrm{NaBH}_{4}$, DMSO, t-BuOK, polysorbate 80 , methanol, sodium cyanide, sodium iodide, ether, $\mathrm{BF}_{3} \cdot \mathrm{Et}_{2} \mathrm{O}$ chloroform, , $\mathrm{SOCl} 2$, acetone, $\mathrm{HCl}$, $\mathrm{NaHCO}_{3}$,resorcinol glacial acetic acid, anhydrous $\mathrm{Na}_{2} \mathrm{SO}_{4}$, toluene, sodium bisulit,sodium acetate aluminum $\mathrm{F}_{254}$ TLC plate.

\section{B. Instrumentation}

Set of reflux, magnetic stirrer, electric heating, Buchi rotary evaporators, vacuum pumps, separating funnel, a set of TLC, UV light, stir bar, desiccator, a set of column chromatography and aparatus others of laboratory glassware..FT - IR spectrometer (Shimadzu FTIR - 820 PCs), GC - MS spectrometer (Shimadzu QP 5000) and H - NMR, $\mathrm{C}^{13}$ NMR (JEOL JNM - MY 60) and GC-MSspectrometer.

\section{Methode}

\section{1) Synthesis of methyleugenol}

Eugenol (41 g, $0.25 \mathrm{~mol}$ ) was placed in a $2 \mathrm{~L}$ glass beaker, added with stirring $120 \mathrm{~mL}$ of $\mathrm{NaOH}$ solution (12 g in 120 $\mathrm{mL}$ of distilled water, $0.3 \mathrm{~mol}$ ). After the last 20 minutes of the addition, the mixture was transferred to a separator funnel and allowed to stand at night. Inorganic layer was extracted with $3 \times 25 \mathrm{~mL}$ petroleum ether. Then transferred into a $1 \mathrm{~L}$ three-necked RB flask equipped with reflux condenser, 
dropping funnel and thermometer. $19.2 \mathrm{~g} \quad(0.15$ mol)dimetilsulfat (DMS) to add part-wise for 1.5 hours at room temperature. The mixture was heated under reflux for 3 hours at $110-120^{\circ} \mathrm{C}$, cooled and then $60 \mathrm{~mL}$ of distilled water was added. The solution was extracted with $3 \times 25 \mathrm{~mL}$ of petroleum ether and then washed with $10 \% \mathrm{NaOH}$.

\section{2) Synthesis of methylisoeugenol}

To a three-neck flask of $100 \mathrm{ml}$ capacity equipped with a dropper funnel, thermometer, cooler balls, silica gel blue, silica tube and magnetic stirrer, water bath fill in t-BuOK $10.1 \mathrm{~g}(0.09 \mathrm{~mol})$ and $25 \mathrm{~mL}$ of DMSO and stirred until dissolved. Once dissolved, enter into the solution $16 \mathrm{~g}$ metileugenol $(0.09 \mathrm{~mol})$ and followed by reflux with stirring for four hours. Results refluxing mixture was poured into ice-water-petroleum ether (1:1) in a separating funnel and shaken for five minutes. Petroleum ether layer was separated.

\section{3) Synthesis of 3,4 - dimethoxybenzaldehide}

To a three-neck flask of $500 \mathrm{ml}$ capacity equipped with a cooling balls, thermometer, stirrer and ice bath enter $5.5 \mathrm{~g}$ ( $0.031 \mathrm{~mol}$ ) metilisoeugenol , $80 \mathrm{~mL}$ of distilled water , 3 $\mathrm{mL}$ of glacial acetic acid , $8 \mathrm{~g}$ of $50 \% \mathrm{H}_{2} \mathrm{SO}_{4}, 0.15$ polysorbate $80 \mathrm{~g}$ catalyst and $150 \mathrm{~mL}$ of dichloromethane . The mixture was stirred until homogeneous, then added $25 \mathrm{~g}$ ( $84.9 \mathrm{mmol}$ ) $\mathrm{K}_{2} \mathrm{Cr}_{2} \mathrm{O}_{7}$ and the temperature was kept less than $30{ }^{0} \mathrm{C}$. After all $\mathrm{K}_{2} \mathrm{Cr}_{2} \mathrm{O}_{7}$ was added, the mixture refluxed for 30 minutes and then cooled.Added $50 \% \mathrm{H}_{2} \mathrm{SO}_{4}$ to $\mathrm{pH}$ 1-2 . The organic layer is separated from the water layer . Water layer was extracted with $30 \mathrm{~mL}$ dichloromethane. The organic layer was collected.

\section{4) Synthesis of 3,4-dimethoxybenzyl alcohol}

The 3,4-dimethoxybenzaldehid as much as $0.97 \mathrm{~g}(6 \mathrm{mmol})$ and $50 \mathrm{~mL}$ of methanol is added to the round bottom flask size $100 \mathrm{~mL}$, then added $0.35 \mathrm{~g}(9.2 \mathrm{mmol})$ of sodium borohydrat $\left(\mathrm{NaBH}_{4}\right)$ while stirring. After stirring for one night, the mixture is evaporated to remove methanol. The residue was diluted with $25 \mathrm{~mL}$ of distilled water and extracted with $3 \times 25 \mathrm{~mL}$ dichloromethane. The organic layer at the bottom was collected.

\section{5) Synthesis of 3,4-dimethoxybenzylcyanida}

The 3,4-dimethoxybenzyl alcohol $2.0 \mathrm{~g}$ (12 mmol) in 15 $\mathrm{mL}$ of ether cooled in ice bath to a temperature of $0^{\circ} \mathrm{C}$ was added $5 \mathrm{~g}(18 \mathrm{mmol})$ in $\mathrm{SOCl}_{2}$ drops while stirring with a magnetic stirrer. Continue stirring the mixture at room temperature for 2 hours. The reaction was monitored by TLC analysis. After the reaction is complete, water is added to a solution of $50 \mathrm{~mL}$ of ice, then transferred into a separator flask and extracted with $3 \times 50 \mathrm{ml}$ ether. Organic layer dried with anhydrous sodium sulfate and evaporated to remove the solvent. Halogenated products was obtained directly towards nitrilisation . To a three-neck round bottom flask equipped with a magnetic stirrer, balls and catcher gas cooling, added $1.5 \mathrm{~g}$ of 3,4- dimethoxybenzyl chloride ( $9.5 \mathrm{mmol}), 0.76 \mathrm{~g}$ of sodium cyanide, $0.1 \mathrm{~g}$ of sodium iodide and $5 \mathrm{~mL}$ of dry acetone. The heterogeneous mixture refluxed with vigorous stirring for 20 hours, then cooled and filtered. Filtered residue was washed with acetone. The filtrate obtained was added 5 $\mathrm{mL}$ of toluene and extracted with $3 \times 5 \mathrm{ml}$ of warm water.

\section{6) Synthesis of 3,4-dimethoxyphenylacetic acid}

The 3,4-dimethoxy benzylcyanide 5 grams (30.6 mmol) was reflux with $250 \mathrm{~mL} 2 \mathrm{M} \mathrm{HCl}$ for one hours, cooled overnight at $4^{0} \mathrm{C}$ in the refrigerator, the precipitate which occurred filtered, washed, recrystallized with methanol. Identify the structure of the reaction products using FT-IR, $1 \mathrm{H}$ NMR and GC-MS.

\section{7) Synthesis of 3,4-dimethoxybenzyl-2,4-dihydroxyphenyl} ketone

Resorcinol (0.003 mol, $0.33 \mathrm{~g}$ ) was added to the acid mixture containing 3.4 - dimethoxyphenylacetic $(0.003 \mathrm{~mol}$, $0.5 \mathrm{~g})$ and BF3.Et2O $(4.5 \mathrm{~mL})$. The reaction mixture was refluxed for 1.5 hours and cooled, and added to $60 \mathrm{~mL}$ of water; water layer was extracted with ethyl ether $(3 \times 50 \mathrm{ml})$. The combined ether layer was washed with saturated sodium acetate solution $(30 \mathrm{ml})$ and saturated $\mathrm{NaHCO}_{3}(15 \mathrm{~mL})$, respectively. Layers were separated, and the ether layer was dried with anhydrous $\mathrm{Na}_{2} \mathrm{SO}_{4}$.

\section{RESUlTS AND DISCUSSION}

\section{A. Synthesis of Methyleugenol}

Methyleugenol can be prepared by alkylation of eugenol with dimethyl sulphate as alkylation agent. The product was yellow oil to yield $89.78 \%$. The chromatogram of gas chromatography of methyleugenol showed that the purities of product was $93.61 \%$.

\section{B. Synthesis of Methylisoeugenol}

Methylisoeugenol can be prepared by isomerization of Methyleugenol with t-BuOK and DMSO, was producted as much as $87.24 \%$ rendement. , form of colorless fragrant liquid.Mass spectra of the results showed ion moleculwer peak at $\mathrm{m} \mathrm{/} \mathrm{z} 178$ which is the molecular ion of methylisoeugenol. FT - IR spectra showed absorption characteristics methyleugenol $-\mathrm{CH}=\mathrm{CH}_{2}$ on wave number $995 \mathrm{~cm}^{-1}$ and $912 \mathrm{~cm}^{-1}$., will change form into the cis and trans structures methyleugenol. This change is indicated by the absorption peak at wavenumber $964.4 \mathrm{~cm}^{-1}$ ( cis - form ) and $732.9 \mathrm{~cm}^{-1}$ ( trans - form ) which replaces the absorption characteristics of the $-\mathrm{CH}=\mathrm{CH}_{2}$. 1H NMR spectra are presented peak at 5.7 to $5.9 \mathrm{ppm}$ chemical shift signals an $\mathrm{H}$ atom of the $=\mathrm{CH}-\mathrm{CH}_{3}$ with the appearance of a doublet peak. Peak at $6.1 \mathrm{ppm}$ is the signal region of the proton - $\mathrm{CH}$ $=\mathrm{CH}$ with the appearance of a peak multiplets. Peak at 3.8 ppm chemical shift signals an $\mathrm{H}$ atom from the methoxy group is strengthened by the results of the integration of the equivalent of six hydrogen atoms. Peak at $1.8 \mathrm{ppm}$ with the integration of the three hydrogen atoms showed a signal of the methyl group. Based on data from FT-IR and $1 \mathrm{H}$ - NMR concluded that the compounds produced from the isomerization reaction is methylisoeugenol.

\section{Synthesis of 3,4-Dimethoxybenzaldehide}

Methylisoeugenol was converted to 3,4Dimethoxybenzaldehide by oxidation use $\mathrm{K}_{2} \mathrm{Cr}_{2} \mathrm{O}_{7}$ with a phase transfer catalyst polysorbate $80(\mathrm{KTF})$. KTF needed to accelerate reactions that take place in a two- phase system. Product is a white solid withrendamen $85.36 \%$. The data obtained from the GC - MS showed a molecular ion peak at 
$\mathrm{m} / \mathrm{z} 166$ with a purity of $83.79 \%$. This the same with molecular weight of the compound 3,4dimethoxybenzaldehide. FT-IR spectra of the product was showed typical absorption peak at wave number $1681 \mathrm{~cm}^{-1}$ in the form of sharp bands indicates that the carbonyl group absorption bands in the region supported by 2841 and 2729 $\mathrm{cm}^{-1}$ for the $\mathrm{CH}$ bond of the aldehyde. 1H-NMR spectrum showed the suitability of the oxidation products of chemical shifts. A peak at a chemical shift $(\delta)$ of $9.8 \mathrm{ppm}$ is a characteristic peak for the chemical shift of the aldehyde hydrogen atom. Peaks at chemical shifts $(\delta) 6.9$ to 7.3 hydrogen atoms of aromatic rings, this was confirmed by the results of the integration which is equivalent to three hydrogen atoms. Peak at $3.9 \mathrm{ppm}$ chemical shift signals an $\mathrm{H}$ atom from the methoxy group is strengthened by the results of the integration of the equivalent of six hydrogen atoms. Based on data from FT-IR and 1H-NMR concluded that the compounds resulting from the oxidation reaction is 3,4 Dimethoxybenzaldehide .

\section{Synthesis of 3,4-Dimethoxybenzyl Alcohol}

Reduction of 3,4-dimethoxybenzaldehyde compounds using $\mathrm{NaBH}_{4}$ to produce compounds such as 3,4dimethoxybenzyl alcohol is white liquid with a yield of $98 \%$. Mass spectra of compounds results showed reduction in the molecular ion $\mathrm{m} / \mathrm{z} 168$ which is the molecular ion of 3,4dimethoxybenzyl alcohol. Typical absorption peaks in FTIR spectra showed that the reduction of the carbonyl group of 3,4-dimethoxybenzaldehyde have produced a sharp absorption band is the loss of the carbonyl group at wave numbers $1712.79 \mathrm{~cm}^{-1}$. The absorption peaks are replaced by a broad absorption band in the wavenumber region $3387 \mathrm{~cm}$

${ }^{1}$ which shows the absorption of the hydroxyl group.

$1 \mathrm{H}-\mathrm{NMR}$ analysis showed that peak at the chemical shift

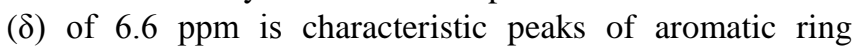
hydrogen atom. Peak at a chemical shift $(\delta) 3.6 \mathrm{ppm}$ is the signal of the methoxy $\mathrm{H}$ atoms were reinforced by the results of integration is equivalent to six hydrogen atoms. Peaks at chemical shifts $(\delta) 4.4 \mathrm{ppm}$ with the integration of two hydrogen atoms showed proton signals of methylene group. Based on the data from FT-IR and 1H - NMR concluded that the process of reduction of 3,4-dimethoxybenzaldehide has produced compounds 3,4- dimethoxybenzyl alcohol .

\section{E. Synthesis of 3,4-Dimethoxybenzylcyanide}

Halogenated compounds 3,4-dimethoxybenzyl alcohol using $\mathrm{SOCl}_{2}$ generates 3,4-dimethoxybenzyl chloride compounds. Chloride compound is reacted with $\mathrm{KCN}$ obtained directly without further purification because the resulting halogen compounds are not stable. The yield of the product obtained by $89.5 \%$. Product nitrilisation further analyzed by a FT-IR, 1H-NMR and GC-MS spectrophotometer. Gas chromatography analysis of the compound nitrilisasi results showed that the purity of the product was $99.24 \%$. Mass spectra of compounds results showed molecular ion at $\mathrm{m} / \mathrm{z} 177$ which is the molecular ion of 3,4 - dimethoxybenzylcyanide .

The compound 3,4-dimethoxybenzylalcohol have a wide absorption peak of hydroxyl groups on the local wave number $3387 \mathrm{~cm}^{-1}$ which will be lost after the substitution reaction with halogen followed by nitrilisation to produce compounds 3,4-dimethoxybenzylcyanide . The compound 3,4-dimethoxybenzylcyanide have FT-IR spectra are typical of the sharp uptake of cyanide groups $(-\mathrm{CN})$ at wave number $2245 \mathrm{~cm}^{-1}$.

A proton in the chemical shifts $(\delta) 6.9 \mathrm{ppm}$ is the characteristic for the aromatic ring hydrogen atom. Proton chemical shift at $3.9 \mathrm{ppm}$ is the absorption of the methoxy $\mathrm{H}$ atoms are strengthened by the integration of the results of the equivalent of six hydrogen atoms. Proton chemical shift at $3.7 \mathrm{ppm}$ with an integration of the two hydrogen atoms of the methylene group signal. Based on data from FT-IR and $1 \mathrm{H}-$ NMR spectroscopy concluded that the compound is produced 3,4-dimethoxybenzylcyanide

\section{F. Synthesis of 3,4-Dimethoxyphenyl Acetic Acid}

The 3,4-dimethoxyphenyl acetic acidas starting material for synhesis keton was derived from 3,4-dimethoxybenzylcyanide. Infrared spectra of this product shows the presence of broad O-H hydroxyl stretch absorption at $3448.72 \mathrm{~cm}^{-1}$ which is supported with the presence of sharp peak $\mathrm{C}=\mathrm{O}$ strecth at $1712.79 \mathrm{~cm}^{-1}$.which showed the absorption of carbonyl groups. Absorption band in the region $3000-3100 \mathrm{~cm}^{-1}$ indicate the presence of a bond $=\mathrm{CH}(\mathrm{sp} 2-\mathrm{s})$ that is reinforced by the absorption band at $1643.35 \mathrm{~cm}^{-1}$ which is the characteristic absorption of the bond between $\mathrm{sp} 2$ carbon clusters $\mathrm{C}=\mathrm{C}\left(1600-1700 \mathrm{~cm}^{-1}\right)$. Absorption band at wave number $1512.19 \mathrm{~cm}^{-1}$ indicates that the double bond derived from an aromatic core (1450-1600 $\left.\mathrm{cm}^{-1}\right)$.. Uptake in the area of $2839.22 \mathrm{~cm}^{-1}-2939,52 \mathrm{~cm}^{-1}$ indicate the presence of vibration Csp3-H bonds are backed by the absorption at $1420 \mathrm{~cm}^{-1}$ is the absorption of the methylene group (-CH2-) and absorption at daerah1396, 46 $\mathrm{cm}^{-1}$ indicates the presence of a methyl group $\left(-\mathrm{CH}_{3}\right)$. The presence of absorption in the region $1000-1300 \mathrm{~cm}^{-1}$ indicate the presence of ether groups (COC) to reinforce the notion that the methyl group is a methoxy group. From the analysis of the IR spectrum characteristic absorption peaks indicate that the product compound is 3,4-dimetoxybenzil carboxylate acid.

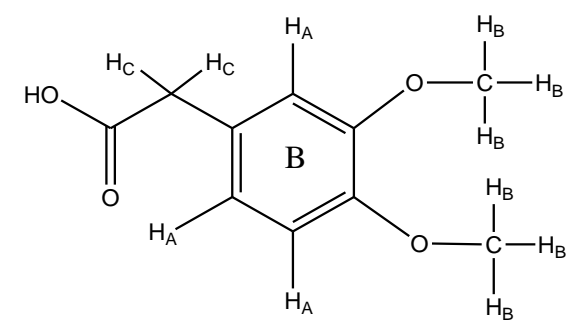

Fig. 1. The structure of 3, 4-dimehoxybenzyl carboxylic acid.

The results of 1H-NMR analysis showed the presence of peaks in the proton chemical shifts $(\delta) 7.15 \mathrm{ppm}$ is the chemical shift of the characteristic peaks for the aromatic ring hydrogen atom. Aromatic protons in the region $\delta 6.0$ to 8.0 is indicated by the appearance of a singlet, this was confirmed by the results of the integration is equivalent to three (HA) hydrogen atom. The peak at $4.2 \mathrm{ppm}$ chemical shift signals an $\mathrm{H}$ atom of the methoxy group (HB) which is reinforced by the results of the integration of the equivalent of six hydrogen atoms. Absorption peaks at $3.8 \mathrm{ppm}$ chemical shift with integration showed two hydrogen atoms is a signal of a methylene group (HC). There are three types of proton magnetic resonance. Chemical shifts $(\delta)$ at $7.15 \mathrm{ppm}$ is stated three aromatic protons at the same chemical shift. Range 
characteristics of aromatic hydrogen appears in the range from 6.5 to $8.5 \mathrm{ppm}$. Chemical shifts $(\delta)$ of protons of a methoxy group at $4.25 \mathrm{ppm}$ indicated, the chemical shift at 11.0 is the proton of the hydroxy group and a carboxyl group at $3.87 \mathrm{ppm}$ chemical shift correlated with the protons of the methylene. Based on spectral data on mass spectrometry, the molecular mass is 196. This corresponds to a molecular mass of 3,4-dimethoxyphenylacetic acid.

\section{G. Synthesis of}

\section{3,4-dDimethoxybenzyl-2,4-dihydroxyphenyl ketone}

The 3, 4-dimethoxybenzyl-2,4-dihydroxyphenyl ketone (deoxybenzoin) obtained by acylation Friedel-Crafts reaction of 3,4-dimethoxybenzyl carboxylic acid (3,4dimethoxy-phenylacetic acid) and resorcinol using boron triflourideetherate $\left(\mathrm{BF} 3-\mathrm{Et}_{2} \mathrm{O}\right)$ as catalyst and solvent.. Acylation reaction for 1.5 hours at $60-80^{\circ} \mathrm{C}$, obtained a solid product having a melting point of $171-172^{\circ} \mathrm{C}$. Rendamen generated from this experiment is $76 \%$. The spectrometry analysis with IR, GC-MS and ${ }^{1} \mathrm{H}$ NMR spectrophotometer of this product was identic with chemdraw estimation of the chemical shift of 3,4-dimethoxybenzyl-2,4-dihydroxyphenyl ketone.

The formation of an acyl cation $(\mathrm{RC}=\mathrm{O})$ from the reaction between 3,4-dimetoxybenzil carboxylic and $\mathrm{BF} 3-\mathrm{Et}_{2} \mathrm{O}$. The Acyl cation formed then reacts with resorcinol

produce

3,4-dimethoxybenzyl-2,4-dihydroxyphenyl ketone as shown in under reaction

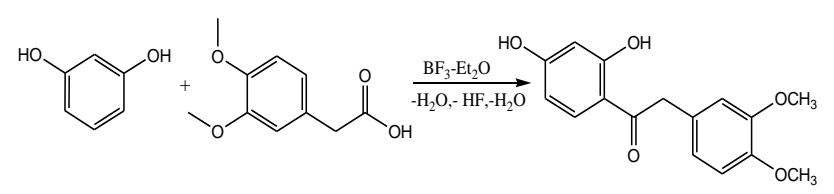

Fig. 2. The reaction synthesis of 3,4 dimethoxybenzyl-2,4-dihydroxyphenyl ketone from 3,4 - dimethoxyphenyl acetic acid and resorcinol.

Infrared spectra of this product showed that this product was 3,4-dimethoxybenzyl-2,4-dihydroxyphenyl ketone compound. This proved by the disappearance of broad $\mathrm{O}-\mathrm{H}$ hydroxyl stretch absorption at $3448.72 \mathrm{~cm}^{-1}$ indicating acylation process between 3,4-dimethoxyphenylacetic acid and resorcinol have been done. The product seen several changes including the loss of carboxylate bands at wavenumber region (v́) $3400 \mathrm{~cm}^{-1}$ which shows that the starting material 3,4-dimetoksibenzil carboxylic acid has undergo substituted electrophilic reaction with resorcinol to 3,4 dimethoxybenzyl-2,4-dihydroxyphenyl ketone. This was confirmed by the appearance of a sharp absorption band at wave number $1712.79 \mathrm{~cm}^{-1}$ which shows the absorption of carbonyl groups Absorption band at wave number 1512.19 $\mathrm{cm}^{-1}$ indicates that the double bond derived from an aromatic core $\left(1450-1600 \mathrm{~cm}^{-1}\right)$. Uptake in the area of 2839.22 $\mathrm{cm}^{-1}-2939,52 \mathrm{~cm}^{-1}$ indicated the presence of vibration Csp3-H bonds are backed by the absorption at $1420 \mathrm{~cm}^{-1}$ is the absorption of the methylene group (-CH2-) and absorption at daerah1396, $46 \mathrm{~cm}^{-1}$ indicates the presence of a methyl group (-CH3). The presence of absorption in the region $1000-1300 \mathrm{~cm}^{-1}$ indicate the presence of ether groups (COC) to a methoxy group.

There are five types of magnetic environtment of the protons. Chemical shift $(\delta)$ appear at two magnetic field correspond to the six aromatic protons in ring $\mathrm{A}$ and $\mathrm{B}$. Chemical shift $(\delta)$ at $6.9 \mathrm{ppm}$ indicated three proton of ring A, and $6.45 \mathrm{ppm}$ indicated two proton of ring B. One aromatic proton from ring A at $7.8 \mathrm{ppm}$. Chemical shift $(\delta)$ of methoxy group indicated by $3.85 \mathrm{ppm}$, than chemical shift at $4.2 \mathrm{ppm}$ correlated to proton of methylen.1H-NMR spectrum of 3,4 dimethoxybenzyl-2,4-dihydroxyphenyl ketone showed significant difference with the spectrum of the 3,4-dimethoxybenzyl carboxylic proton. Peaks at chemical shifts $(\delta) 11 \mathrm{ppm}$ which indicates the hydroxyl group of the carboxyl protons at 3.4-carboxylic dimethoxybenzyl lost after the product is formed.

${ }^{13} \mathrm{C}$-NMR spectroscopic analysis gives an overview of the molecular carbon skeleton synthesis product compounds that will strengthen the results of the analysis of the IR spectrum and $1 \mathrm{H}-\mathrm{NMR} .{ }^{13} \mathrm{C}-\mathrm{NMR}$ spectra of these appear in the absorption signal of the carbonyl carbon, aryl and methoxy. Carbon with oxygen as carbonyl signal appeared at 202.4 ppm. Carbon with oxygen as alcohol aromatic signals appeared at $102.48 \mathrm{ppm}$ and $108.25 \mathrm{ppm}$. Carbon for ether methoxy-OCH3 appeared at $55.45 \mathrm{ppm}$ and $55.48 \mathrm{ppm}$. Methylene carbon appeared at $\delta=43.67 \mathrm{ppm}$.

Based on the spectra data of mass spectrometer, the molecular mass of this produt is 288 . This is likely to be the molecular mass of 3,4-dimethoxybenzyl-2,4-dihydroxyphenyl ketone.

\section{CONCLUSION}

Preparation of 3, 4-dimethoxybenzyl cyanide basic ingredients of eugenol can be done through the stages of eugenol methylation reaction, isomerization, oxydation, reduction, halogenation and nitrilisation. Methylation process of eugenol produced methyleugenol from as much as $89.78 \%$. Isomerization of methyleugenol yield methylisoeugenol $87.24 \%$. 3, 4-dimethoxybenzaldehyde obtained from the oxidation process of methylisoeugenol as much as $85.36 \%$. Reduction of 3, 4-dimethoxybenzaldehida using $\mathrm{NaBH}_{4}$ produces 3, 4-dimethoxybenzyl alcohol as much as $98 \%$. Halogenated 3, 4-dimethoxybenzyl alcohol produces 3,4-dimethoxybenzylchloride which reacted further to 3.4-dimethoxybenzylcyanide without prior separation as much as $89.5 \%$ with a purity of $99.24 \%$. Acylation of 3,4-dimethoxyphenylacetic acid was resulted 3,4-dimethoxybenzyl-2,4-dihydroxyphenyl ketone76\% at melting point $171-172{ }^{\circ} \mathrm{C}$.

\section{ACKNOWLEDGMENT}

My thanks go to the Ministry of Education and Culture that has supported the fund's research universities seed from GadjahMada University through LPPM. UGM.

\section{REFERENCES}

[1] J. Liggins, L. J. Bluck, S. Runswick, C. Atkinson, W. A. Coward, and S. A. Bingham, "Daidzein and genistein content of fruits and nuts," $J$. Nutr. Biochem., vol. 11, pp. 326-331, 2000.

[2] A. Kampköttera, Y. Chovoloua, A. Kulawika, E. Röhrdanzc, N Weberb, P. Prokschb, and W. Wätjena, "The isoflavonedaidzein possesses no antioxidant activities in cell-free assays but induces the antioxidant enzyme catalase," Nutrition Research, vol. 28, pp. 620-628, 2008. 
[3] T. Rukachaisirikul, P. Innok, N. Aroonrerk, W. Boonamnuaylap, S. Limrangsun, C. N. Boonyon, and A. Suksamrarn Woonjina, "Antibacterial pterocarpans from erythrinasubumrans," Journal of Etnopharmacology, vol. 110, no. 1, pp. 171-175, 2007.

[4] D. L. Alekel, S. G. Alyson, T. P. Charles, B. H. Kathy, W.S. Jeanne, T. Thoshiya, "Isoflavone-rich soy protein isolate attenuate bone loss in the spine of perimenopausalthumbar women," Am. J. Clin. Nut, vol. 72, pp. 844-852, 2006.

[5] E. J. Choi, and G. H. Kim, "Daidzein causes cell cycle arrest at the G1 and G2/M phases in human breast cancer MCF-7 and MDA-MB-453 cells," Phytomedicine, vol. 15, pp. 683-690, 2008

[6] T. Horie, M. Sasagawa, F. Torii, Y. Kawamura, and K. Yamashita, "Study of the Selective O-alkylation and dealkylation of Flavonoids XX. A Convenient Method for Synthesizing 5,6,7-trihydroxyisoflavones and 5,6-dihydroxy-7-methoxyisoflavones," Chem. Pharm. Bull., vol. 44, no. 3, pp. 486-491, 1996.

[7] S. Antus, L. Farkas, Á. Gottsegen, Z. Kardos-Balogh, and M. Nógrádi, "Oxidative Rearrangement of chalcones by Thallium (III) Nitrate, VI1 Synthesis of the is of lavonoidsJamaicin and Leiocarpin," Chemische Berichte, vol. 109, no. 12, pp. 3811-3816, 2006.

[8] V. Barve, F. Ahmed, S. Adsule, S. Banerjee, S. Kulkarni, P. Katiyar, C.E. Anson, A. K. Powell, S. Padhye, and F. H. Sarkar, "Synthesis, molecular characterization, and biological activity of novel synthetic derivatives of chromen-4-one in human cancer cells," J. Med. Chem. vol. 49, pp. 3800-3808, 2006.

[9] T. J. Faria, L. G. F. Silva, J. D. S. Filho, E. Chiari, and A. B. Oliveira, "Synthesis and trypanocidal activity of 7,2 '-dioxygenatedisoflavones and oxypropanolamine derives," J. Braz. Chem. Soc., vol. 16, no. 6B, pp. $1415-1419,2005$

[10] C. L. Thoruwa, T. T. J. Song Hu, A. L. Simon, and P. A. Murphy, "A simple synthesis of 7,4 '-dihydroxy-6-methoxyisoflavone, glycitein, the Third Soybean Isoflavone," J. Nat. Prod., vol. 66, pp. 149-151, 2003.

[11] M. Yato, T. Ohwada, and K. Shudo, "Requirements for houben-hoesch and gattermann reactions. involvement of diprotonated cyanides in the reactions with benzene," J. Am. Chem. Soc., vol. 113, pp. 691-692, 1991.

[12] Y. C. Chang, M. G. Nair, W. G. Helferich, and R. C. Santell, "Microwave Mediated Synthesis of anticarcinogenicisoflavones from Soybeans," J. Agric. Food Chem., vol. 42, pp. 1869-1871, 1994.

[13] H. Singh and R. Pratap, " A convenient one-pot synthesis of 7-hydroxy-isoflavones from resorcinol with substituted phenylacetic acids," Tetrahedron Letters, vol. 7, issue 46, pp. 8161-8163, November 2006.

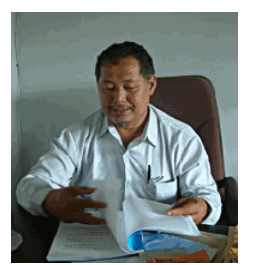

Matsjeh S. received his postdoctoral degree in University Sains Malaysia, Malaysia, from January 1983 to January 1984. His thesis was Natural Product of Traditional Medicine of Malaysia. He received his doctor degree in University Sains Malaysia, Malaysia, from January 1980 to January 1983, and master degree in the Department of Chemistry/FMIPA UGM, Gadjah Mada University, Indonesia, from January 1973 to January 1975. His research interests include flavonoid and alkaloid synthesis compounds basis using the results of the Indonesia, eluicidation structure of compound isolation from traditional Indonesian medicinal plants. He was awarded the Charter Awards loyalty as faithfulness in Anugrah on serve for 25 years, Gadjah Mada University, 2000. Alerts Satyalacana Karya Satya Honorary, 20 years old, Charter Honorary President of the Republic of Indo, 1999. Charter Award For Example Lecturer Faculty of Mathematics and Natural Sciences UGM, Gadjah Mada University, 1989. 